\title{
Urrets-Zavalia Syndrome Following Cataract Surgery
}

\author{
Shimon Kurtz ${ }^{a}$ Maayan Fradkin ${ }^{b}$ \\ ${ }^{a}$ Department of Ophthalmology, Tel Aviv Sourasky Medical Center, Tel Aviv, Israel; bSackler \\ Faculty of medicine, Tel Aviv University, Tel Aviv, Israel
}

\section{Keywords}

Urrets-Zavalia syndrome · Fixed and dilated pupil · Iris atrophy

\begin{abstract}
We describe a case of Urrets-Zavalia syndrome (UZS) in a healthy 56-year-old woman who underwent femtosecond-assisted phacoemulsification with intraocular lens implantation in both eyes. One month after an uneventful postoperative course in the left eye, the right eye was operated. Dilated pupil which was nonreactive to light appeared on day 21 postoperatively. This was discovered upon examination following anterior chamber inflammatory reaction which occurred 2 weeks following her surgery. Our case report emphasizes the importance and danger in developing UZS even if the reaction in the anterior chamber does not occur immediately after surgery. In addition, the importance of intraocular pressure follow-up in the period after UZS is acknowledged.
\end{abstract}

\section{Introduction}

Urrets-Zavalia syndrome (UZS) was first described in 1963 as the appearance of a fixed and dilated pupil following penetrating keratoplasty for keratoconus in patients receiving atropine [1]. Currently, it is widely accepted that UZS can occur as a complication of other surgical interventions, including trabeculectomy, phakic intraocular lens implant, argon laser peripheral iridoplasty, trans-scleral diode laser cyclophotocoagulation, deep anterior lamellar keratoplasty, Descemet-stripping automated endothelial keratoplasty, Descemet membrane endothelial keratoplasty, etc. [2-8]. Overall incidence reported after cataract surgery is $8.2 \%$ [9]. Mechanism of UZS has still not been fully determined, and there are numerous and conflicting risk factors. One of the risk factors described is anterior chamber inflammatory reaction secondary to toxic anterior segment syndrome (TASS). TASS typically causes fixed dilated pupil on the first postoperative day immediately with the presentation of inflammation [10].

\section{Karger $\stackrel{\text { ! }}{=}$}


We report a case of a 56-year-old female, with a postoperative anterior chamber inflammatory reaction which occurred 2 weeks following her cataract surgery. The subsequent fixed pupil dilation and iris atrophy occurred 7 days after surgery; their appearance did not coincide at the same time of inflammation.

\section{Case Report}

A 56-year-old woman, with nonsignificant past medical history, presented in our clinic with an ocular history of bilateral myopia (-6D). The patient underwent femtosecond laserassisted cataract surgery in both eyes. One month after an uneventful postoperative course in the left eye, the right eye was operated on as well. Prior to the operation, there were no pathological findings on slit-lamp examination. The surgical procedure was performed under topical anesthesia; standard phacoemulsification surgical technique was performed in both eyes with implantation of Acrysof Single Piece intraocular lens within the capsular bag. The patient had normal symptoms at 1-day postoperative exam include foreign body sensation, ache, and redness. She received topical Ofloxacin and Dexamethasone Sodium Phosphate eyedrops 4 times daily for 1 week with gradual reduction in Dexamethasone eyedrops dose.

Two weeks after her second eye cataract operation, the patient complained of visual discomfort in her right eye and a bothersome glare at night. On examination, her right eye appeared with anterior chamber inflammatory reaction $(3+$ cell) with no fibrin or hypopyon. No further findings were found in her examination. She was subsequently treated with an increased dose of Dexamethasone eyedrops to 6 times daily. Left eye examination showed no significant findings. On a follow-up examination 1 week later, there was an improvement in her anterior chamber reaction (1+ cell); however, her pupil was found to be fixed and dilated $(6 \times$ $9 \mathrm{~mm}$ ) with no response to pilocarpine 2\%. There was a diffuse iris atrophy (shown in Fig. 1), and pigment was found in the inferior cornea and lens, mainly on the inferior capsulorhexis line (shown in Fig. 2). Gonioscopy examination of the right eye revealed a mostly closed angle with the exception of the nasal side. In addition, peripheral anterior synechiae were seen (shown in Fig. 3). Left eye angle was wide open. At the time of the examination, the fundus did not reveal any significant pathology and intraocular pressure (IOP) measured was $12 \mathrm{~mm} \mathrm{Hg}$ in each eye.

On her follow-up visit 1 month postoperatively, no intraocular inflammation was observed. The patients developed pseudophakic cystoid macular edema in both eyes with only slight reduction of visual acuity. The foveal hydration was absorbed in 4 weeks of topical Nepafenac and Dexamethasone eyedrops. After this treatment period, visual acuity returned to her baseline before the appearance of cystoid macular edema.

At the same follow-up, IOP measurements were different between 2 eyes - $19 \mathrm{~mm} \mathrm{Hg}$ in her right eye and $12 \mathrm{~mm} \mathrm{Hg}$ in her left eye. Her right pupil remained fixed dilated throughout

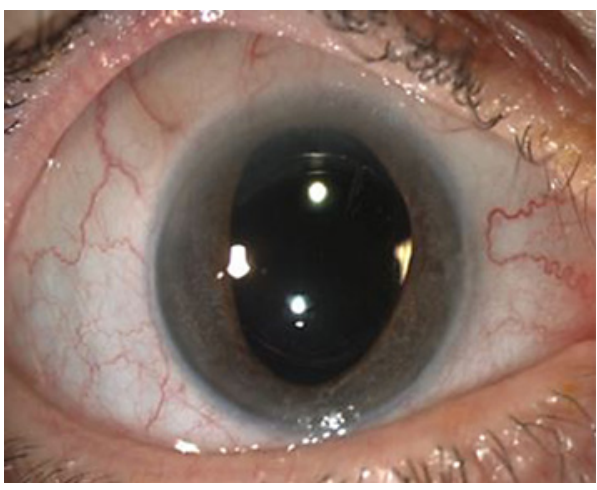

Fig. 1. Right eye - Iris atrophy.

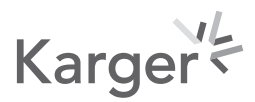



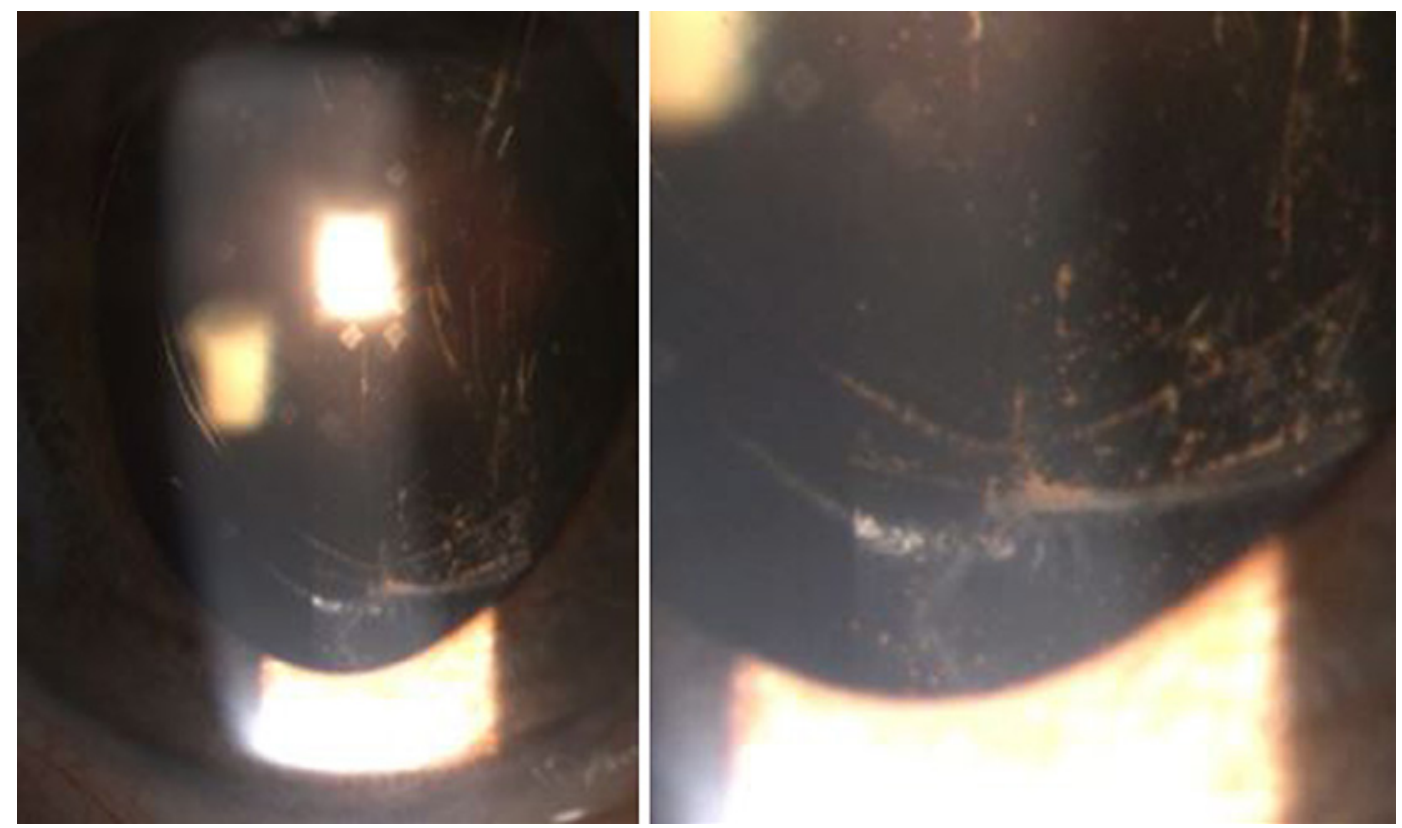

Fig. 2. Right eye - Pigment cells in the inferior cornea and lens, mainly on the inferior capsulorhexis line.
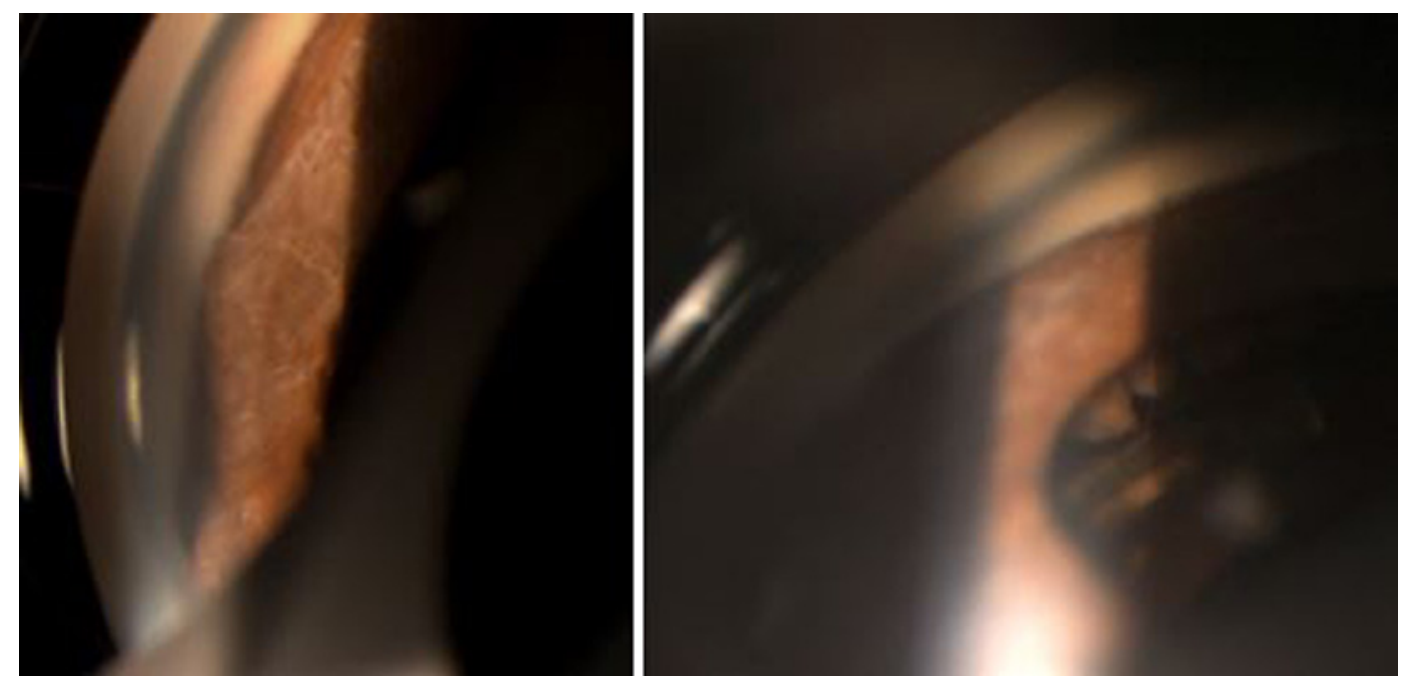

Fig. 3. Gonioscopy examination of the right eye revealed mostly closed angle except the nasal side and PAS. PAS, peripheral anterior synechiae.

2 months of postoperative follow-up. Three months postoperatively, there was no change in her examination or in her IOP.

\section{Discussion}

UZS is a rare postoperative complication characterized by a fixed dilated pupil with accompanying iris atrophy. Currently, there exist approximately one hundred published case reports. Risk factors and mechanisms are still unclear. Possible risk factors for a delayed 
inflammatory reaction might be TASS, endophthalmitis, and remnants of the cataract which can lead to release of inflammatory.

The reason for her late inflammatory reaction is still unknown, but we believe it was secondary to TASS as she improved with only increased dose of Dexamethasone eyedrops. In addition, remnants of the cataract were not found in her examination.

Anterior chamber reaction immediately (within $24 \mathrm{~h}$ ) after surgery secondary to TASS has been reported to be a risk factor for developing UZS [10]. However, late onset cases of TASS occurring months after cataract surgery as documented in literature are not rare [11].

Our case is unique since although our patient developed anterior chamber reaction, to our knowledge, this is the first case in which UZS occurred 1 week after anterior chamber inflammatory reaction, which subsequently developed 2 weeks after the surgery, and not immediately after the surgery. Additional associated risk factor such as increased IOP during or immediately after surgery, or viscoelastic material remaining in the eye was not present in this patient. Other unique findings of UZS which have been reported including peripheral synechiae and pigmentary dispersion also occurred in our patient [9].

Two months after identifying the syndrome (60 days after her operation), IOP values were different between the right and left eyes. Recent research shows that progression to secondary glaucoma is reportedly observed in approximately one-quarter of cases [9]. Although it should not be considered a definitive characteristic for the syndrome, it is important that the IOP should be monitored following these cases.

\section{Acknowledgement}

This manuscript does not include any nonauthor contributors to acknowledge.

\section{Statement of Ethics}

The written informed consent was obtained from the patient for publication of this case report and any accompanying images.

\section{Conflict of Interest Statement}

The authors of this manuscript do not have any conflict of interest to declare.

\section{Funding Source}

This manuscript did not receive any funding.

\section{Author Contributions}

The authors Dr. Shimon Kurtz and Dr. Maayan Fradkin contribute to this case report manuscript equally. Dr. Shimon Kurtz provided critical feedback and helped shape the report. 
Kurtz and Fradkin: Urrets-Zavalia Syndrome Following Cataract Surgery

\section{References}

1 Foroutan A, Tabatabaei SA, Soleimani M, Nekoozadeh S. Urrets-Zavalia syndrome in different methods of keratoplasty. Int J Ophthalmol. 2016 Sep;9(9):1358-60.

2 Park GS, Won YK, Kim KN, Lee YH, Kim C. Urrets-Zavalia syndrome following trabeculectomy. J Korean Ophthalmol Soc. 2020;61(2):221.

3 Jovanovic V, Nikolic L. Urrets-Zavalia syndrome after deep anterior lamellar keratoplasty. Vojnosanit Pregl. 2016 Oct; 73(10):973-5.

4 Vieira GM, Vieira FJ, Ritch R. Urrets-Zavalia syndrome after diode laser transscleral cyclophotocoagulation. J Glaucoma. 2017 Jul;26(7):678-82.

5 Riks IA, Papanyan SS, Astakhov SY, Dzhaliashvili GZ. Urrets-Zavalia syndrome after penetrating keratoplasty. Ophthalm J. 2018 Dec;11(4):99-103.

6 Holtmann C, Spaniol K, Geerling G. Urrets-Zavalia syndrome after descemet membrane endothelial keratoplasty. Eur J Ophthalmol. 2015 Sep;25(5):e75-7.

7 Yuzbasioglu E, Helvacioglu F, Sencan S. Fixed, dilated pupil after phakic intraocular lens implantation. J Cataract Refract Surg. 2006 Jan;32(1):174-6.

8 Espana EM, Ioannidis A, Tello C, Liebmann JM, Foster P, Ritch R. Urrets-Zavalia syndrome as a complication of argon laser peripheral iridoplasty. Br J Ophthalmol. 2007 Apr;91(4):427-9.

9 Magalhães OA, Kronbauer CL, Müller EG, Sanvicente CT. Update and review of Urrets-Zavalia syndrome. Arq Bras Oftalmol. 2016 Jun;79(3):202-4.

10 Nizamani NB, Bhutto IA, Talpur KI. Cluster of Urrets-Zavalia syndrome: a sequel of toxic anterior segment syndrome. Br J Ophthalmol. 2013 Aug;97(8):976-9.

11 Park CY, Lee JK, Chuck RS. Toxic anterior segment syndrome-an updated review. BMC Ophthalmol. 2018 Oct; 18(1):1-9. 